\title{
Factors influencing adherence to
}

\section{psychopharmacological medications in psychiatric patients: a structural equation modeling approach}

This article was published in the following Dove Press journal:

Patient Preference and Adherence

28 March 2017

Number of times this article has been viewed

\author{
Carlos De las Cuevas' \\ Jose de Leon ${ }^{2-4}$ \\ Wenceslao Peñate ${ }^{5}$ \\ Moisés Betancort ${ }^{5}$ \\ 'Departamento de Medicina \\ Interna, Dermatología y Psiquiatría, \\ Universidad de La Laguna, Canary \\ Islands, Spain; ${ }^{2}$ Mental Health \\ Research Center at Eastern State \\ Hospital, Lexington, KY, USA; \\ ${ }^{3}$ Psychiatry and Neurosciences \\ Research Group (CTS-549), Institute \\ of Neurosciences, University of \\ Granada, Granada, Spain; ${ }^{4}$ Biomedical \\ Research Center in Mental Health \\ Net (CIBERSAM), Santiago Apostol \\ Hospital, University of the Basque \\ Country, Vitoria, Spain; ${ }^{5}$ Departamento \\ de Psicología Clínica, Psicobiología y \\ Metodología, Universidad de La \\ Laguna, Canary Islands, Spain
}

Purpose: To evaluate pathways through which sociodemographic, clinical, attitudinal, and perceived health control variables impact psychiatric patients' adherence to psychopharmacological medications.

Method: A sample of 966 consecutive psychiatric outpatients was studied. The variables were sociodemographic (age, gender, and education), clinical (diagnoses, drug treatment, and treatment duration), attitudinal (attitudes toward psychopharmacological medication and preferences regarding participation in decision-making), perception of control over health (health locus of control, self-efficacy, and psychological reactance), and level of adherence to psychopharmacological medications. Structural equation modeling was applied to examine the nonstraightforward relationships and the interactive effects among the analyzed variables.

Results: Structural equation modeling demonstrated that psychiatric patients' treatment adherence was associated: 1) negatively with cognitive psychological reactance (adherence decreased as cognitive psychological reactance increased), 2) positively with patients' trust in their psychiatrists (doctors' subscale), 3) negatively with patients' belief that they are in control of their mental health and that their mental health depends on their own actions (internal subscale), and 4) positively (although weakly) with age. Self-efficacy indirectly influenced treatment adherence through internal health locus of control.

Conclusion: This study provides support for the hypothesis that perceived health control variables play a relevant role in psychiatric patients' adherence to psychopharmacological medications. The findings highlight the importance of considering prospective studies of patients' psychological reactance and health locus of control as they may be clinically relevant factors contributing to adherence to psychopharmacological medications.

Keywords: attitude to health, medication adherence, health behavior, internal-external control, model, statistical, psychiatry

\section{Plain language summary}

Why was the study done? There are factors that influence whether psychiatric patients take their medications or not.

What did the researchers do? They studied 966 consecutive psychiatric outpatients. In these patients, they studied: 1) sociodemographic measures, 2) clinical measures, 3) measures of attitude toward psychiatric medications, 4) patient perceptions of which factors control their health, and 5) self-reports from patients about adherence or lack of adherence to psychiatric prescriptions. All of these measures were explored using a complex mathematical method to build a mathematical model. 
What did the researchers find? According to our mathematical model, several factors influence whether patients take their psychiatric medications, based on their self-report. One of the major factors is the patient's perception of what influences control their health. If patients trust their doctors, it increases the possibility that they will take their medications. When patients are convinced that their mental health mainly depends on their own actions, they are less prone to take their medications.

What do these results mean? After accounting for other factors, patient perception of what controls their health is one of the factors that influences whether they take their psychiatric medications, according to their self-report.

\section{Introduction}

Accurate diagnosis and effective psychopharmacological medications are essential to good outcomes and quality of life for psychiatric patients. However, patients' failure to take medications as prescribed, usually described as nonadherence, ${ }^{1}$ represents a significant barrier to effective psychopharmacological treatment. Nonadherence to adequate psychopharmacological medications remains a major challenge in current clinical psychiatric practice. ${ }^{2}$

Although the rates of nonadherence to psychopharmacological medications differ based on definition and measurement, it has been estimated that overall nonadherence rates for antidepressants in psychiatric populations range from $13 \%$ to $56 \% .^{3-7}$ In the same way, the prevalence of antipsychotic medication nonadherence in patients with schizophrenia has reached a mean rate of $50 \%-61 \%,{ }^{8,9}$ while estimates of nonadherence rates for long-term prophylactic pharmacotherapy for bipolar disorders range from $20 \%$ to $60 \%$, with a median of $40 \% .^{10,11}$

Nonadherence to psychopharmacological medications has been found to predict worse outcomes for psychiatric patients, ${ }^{12}$ including relapse, rehospitalization and delays in achieving remission, ${ }^{13,14}$ violence such as reported aggression and arrests, ${ }^{15}$ suicide, ${ }^{16}$ and premature death. ${ }^{17,18}$ Furthermore, a relationship has been evidenced between nonadherence to psychopharmacological medications and the economic costs of psychiatric disorders, with higher rates of nonadherence leading to higher treatment costs. ${ }^{19-21}$

Previous research has shown that treatment adherence is a multidimensional phenomenon determined by the interplay of different factors including patient-related, environmentrelated, medication-related, disorder-related, and other treatment-related factors. ${ }^{22}$ Although previous research has shown direct associations between sociodemographic, ${ }^{23,24}$ clinical, ${ }^{23-26}$ attitudinal,,${ }^{27,28}$ and perceived health control variables, ${ }^{29,30}$ the mechanisms underlying these associations are still undetermined. A recent review provided an historical overview of the research on medication adherence in psychiatry. ${ }^{31}$

Structural equation modeling (SEM) is a multivariate statistical technique used for empirical validation of theories and quantification of causal effects, especially in the social sciences, on nonexperimental data, when relations are of the linear type..$^{32,33}$ These models do not prove causality, but help the researcher in decision-making and rejecting causal hypotheses when they contradict the data, that is, the underlying covariance structure or correlations between variables.

The present study aims to explore the processes by which these variables are related to treatment adherence in routine clinical care in outpatient psychiatry. The identification of potential mediators could serve as important intervention targets for improving psychiatric patients' adherence to treatment. The high prevalence of nonadherence in psychiatric clinical practice, its potentially severe clinical consequences, and the associated high costs make the study of this phenomenon a priority issue.

We hypothesized that perceived health control variables, namely self-efficacy, health locus of control, and psychological reactance, would be related to psychiatric patient treatment adherence and would be a mediating effect on the relationship between sociodemographic and clinical variables and adherence to psychopharmacological medications.

\section{Methods}

\section{Participants and procedures}

The ethics committee of the Canary Islands Health Service approved this study, and all the participating patients provided written informed consent. A cross-sectional design was used for this study. A total of 966 consecutive psychiatric outpatients attending two Community Mental Health Centers from October 2013 to April 2014 consented to participate in the study ( $81 \%$ response rate). Patients were eligible for inclusion in the study if they were at least 18 years old, were diagnosed by their psychiatrist with psychiatric disorders using the International Classification of Diseases, Tenth Edition (ICD-10), ${ }^{34}$ and were being treated with psychopharmacological medications.

\section{Measures}

\section{Sociodemographic characteristics and clinical variables}

Age, gender, educational level (elementary school, secondary school, or university degree), diagnoses, psychiatric treatment duration, psychopharmacological medications prescribed, 
and number of different drugs used were assessed through a questionnaire.

\section{Instruments}

Psychiatric patients' attitudes toward their psychopharmacological medications were assessed using the validated Spanish version of the Drug Attitude Inventory - 10 Items (DAI-10). ${ }^{35,36}$ DAI-10 consists of 10 items with scores ranging from a minimum of -10 to a maximum of 10 . A positive total score means a positive attitude, while a negative total score indicates a negative attitude. Patients were grouped according to their DAI-10 total score. Those who had total scores $>0$ were classified as "pharmacophilic", and those with negative scores were classified as "pharmacophobic".

The amount of decision-making control that patients want to take concerning their psychopharmacological medications was assessed using the validated Spanish version of the Control Preferences Scale (CPS). ${ }^{37,38}$ Three scores are possible, based on the patient's two most preferred roles: active, collaborative, or passive.

Patients' perceptions about who or what controls their psychiatric disorder outcomes, called the health locus of control, was assessed using the validated Spanish version of the Multidimensional Health Locus of Control scale, Form C (MHLC-C). ${ }^{39,40}$ The MHLC-C is an 18-item self-report scale composed of four subscales: an internal locus of control subscale (Internality) and three external locus of control scales (Chance, Doctors, and Other [powerful] People) that measure control variables with regard to participants' health. High scores represent beliefs in high levels of control ascribed to their corresponding dimensions.

Patients' general self-efficacy was assessed using the validated Spanish version of the General Self-Efficacy Scale (GSE). ${ }^{41,42}$ GSE is a 10 -item self-report scale with scores ranging from 10 to 40 , with the highest scores indicating high self-efficacy.

Patients' differences in reactance proneness, that is, individuals' trait propensity to experience psychological reactance, was assessed using the validated Spanish version of the Hong Psychological Reactance Scale (HPRS). ${ }^{43,44}$ According to the concept of psychological reactance, ${ }^{43}$ when an individual's freedom is threatened, the individual will be motivated to restore his or her perceived loss of freedom. HPRS is a 14-item self-report questionnaire composed of two subscales: cognitive and affective.

Self-reported adherence to prescribed psychopharmacological medication was assessed using the validated Spanish version of the 8-item self-report, the Morisky Medication
Adherence Scale (MMAS-8). ${ }^{45,46}$ Total scores on the MMAS-8 range from 0 to 8 , with scores of 8 reflecting high adherence, 7 or 6 reflecting medium adherence, and $<6$ reflecting low adherence. Permission to use the scale was granted by Donald Morisky, the copyright holder of the instrument.

\section{Data analysis}

The data were analyzed using two different types of analysis: binary logistic regression and an SEM approach. First, high adherence was modeled according to two types of variables: background variables (sociodemographic variables) and mediating variables (clinical, attitudinal and perceived health control variables) (Figure 1). The effect of these variables was analyzed through a series of binary logistic regressions to predict the role of each variable in adherence to treatment, according to the MMAS-8. In a second group of analyses, an SEM was carried out, taking into account factors that may influence adherence, including sociodemographic, clinical, attitudinal, and perceived health control variables. Model invariance was checked according to DAI-10 categorization of pharmacophobic and pharmacophilic patients and type of diagnosis. Prior to applying the structural model, the assumption of multivariate normality was tested. The values for the main coefficients were found by using: the $\chi^{2}$ Goodness of Fit Index (GFI), the $\chi^{2}$ Adjusted Goodness of Fit Index (AGFI), the $\chi^{2} / d f$ corrections, the Normed Fit Index (NFI), the Comparative Fit Index (CFI), and the Root Mean Square Error of Approximation (RMSEA). To interpret a good fit of the data, we assumed that the RMSEA value must be close to or less than 0.05 to indicate a good fit, and that values as high as 0.08 indicate a reasonable fit. NFI values equal to or higher than 0.80 indicate a good fit. Regarding the CFI and GFI, values close to or greater than 0.95 must be attained.

$\mathrm{R}$ Core Team $^{47}$ and ULLRToolbox ${ }^{48}$ were used for descriptive statistics, and the Latent Variable Analysis free statistics package ${ }^{49}$ was used for the SEM.

\section{Results}

Of the 966 consecutive psychiatric outpatients who participated in this study, almost two-thirds were women (63\%). The mean age of participants was 49.6 years (standard deviation $[\mathrm{SD}]=13.8$ ). Educational levels of the patients were as follows: $9 \%$ could only read and write, $35 \%$ had completed elementary school, 37\% had completed secondary school, and $19 \%$ had a university degree. Concerning diagnoses, 19\% had a primary diagnosis of schizophrenia, 12\% had bipolar disorder, 48\% had depressive disorders, 17\% had anxiety disorders, and $3 \%$ had personality disorders. The average 


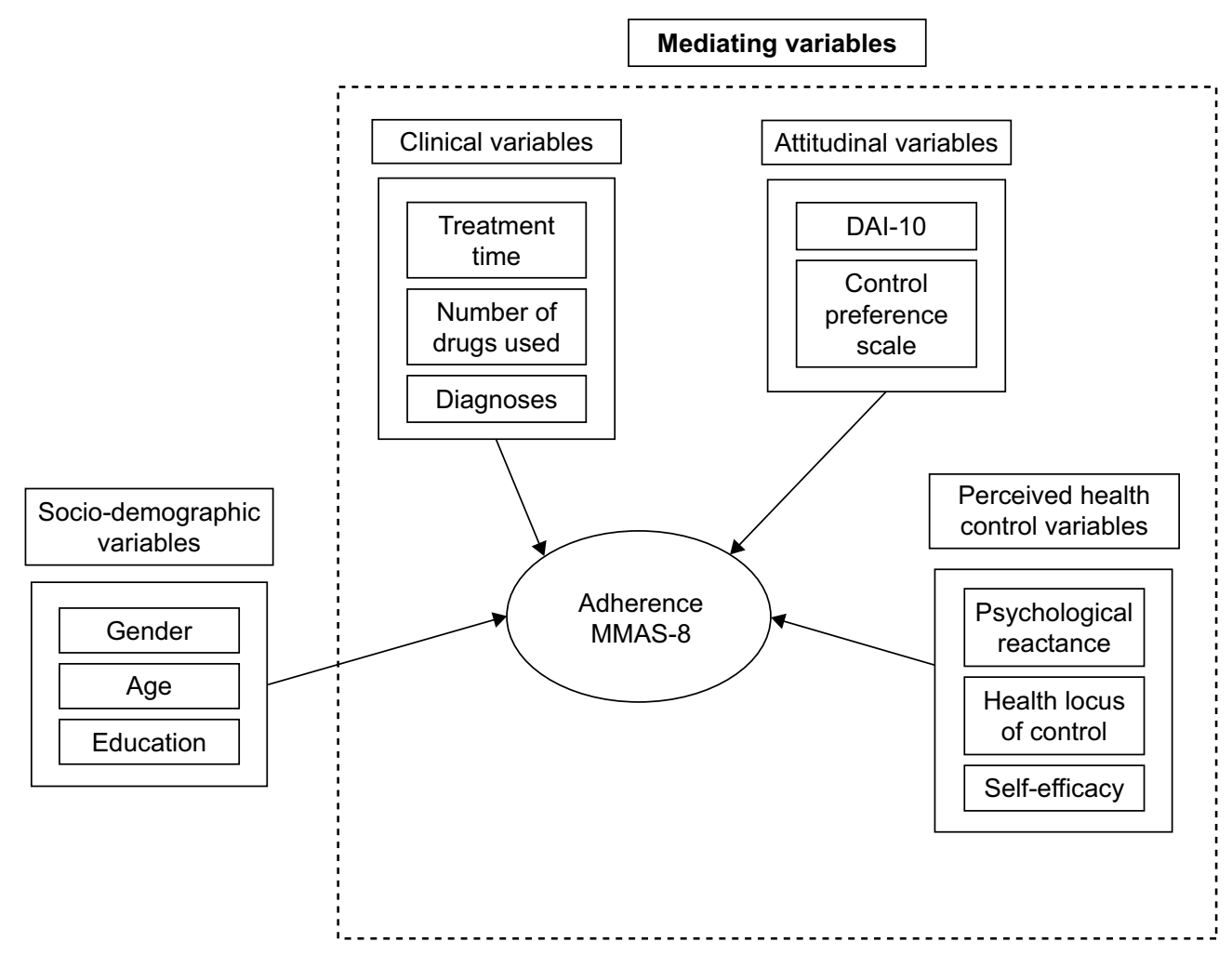

Figure I Research framework and model construction.

Note: Use of the MMAS-8 is protected by the US copyright laws. Permission for use is required. A licensure agreement is available from Donald E Morisky, ScD, ScM, MSPH, Professor, Department of Community Health Sciences, UCL A School of Public Health, 650 Charles E Young Drive South, Los Angeles, CA 90095-I772; dmorisky@gmail.com.

Abbreviations: DAI-I0, Drug Attitude Inventory - 10 Items; MMAS-8, Morisky Medication Adherence Scale.

treatment duration was $112 \pm 100$ months (range: 1-400). The mean number of psychopharmacological medications prescribed was $2.9 \pm 1.4$ (range: $1-8$ ). The rate of polypharmacy was $87 \%$, with $27 \%$ receiving two medications, $26 \%$ receiving three, $18 \%$ receiving four, and $16 \%$ receiving five or more psychopharmacological medications. The mean total medication adherence score was $6.4(\mathrm{SD}=1.6)$, with $25 \%$ of psychiatric patients self-reporting a high level of adherence, $47 \%$ self-reporting medium adherence, and $28 \%$ self-reporting low adherence.

\section{Logistic regression models}

Table 1 shows the logistic regression models built to predict adherence after the successive introduction of the sociodemographic, clinical, attitudinal, and perceived health control variables.

The first logistic regression model built to predict adherence according to sociodemographic variables showed a strong link between gender, age and level of education, and treatment adherence to psychopharmacological medications. According to this analysis female gender, older age, and university degree increased adherence to treatment.
In the second logistic regression model, after adding the clinical variables (medication used, number of drugs used, treatment duration, and diagnosis) (Model 2), age and educational level continued to positively influence treatment adherence, while diagnosis of anxiety disorder implied less adherence. Medication use, number of drugs or treatment duration, and diagnosis of depression did not reach significance.

In Model 3, after adding the attitudinal variables, the variables increasing adherence were age and education (which continued to be significant even after the second model) and, the new significant one, pharmacophilia, while diagnoses of anxiety continue to be significantly associated with lower adherence to psychopharmacological medications. The CPS variable was not significant.

Finally, the fourth model, after adding to prior variables the perceived health control variables (health locus of control, general self-efficacy, and psychological reactance), showed that age was the only significant demographic variable remaining in the model that predicted a high level of adherence to treatment, while university degree was marginally significant. Clinical variables did not reach a significant 
Table I Successive logistic regression models for sociodemographic, clinical, attitudinal, and perceived health control variables

Model I Sociodemographic variables

$\begin{array}{llll}\text { Variables } & B(\mathrm{SE}) & \mathrm{OR}^{\mathrm{a}} & 95 \% \mathrm{Cl}\end{array}$

$\begin{array}{llll}\text { Female gender } & 0.057(0.15) & 1.06 & 0.78-1.43\end{array}$

Age $\quad 0.03 *(0.005) \quad 1.03 \quad 1.02-1.04$

$\begin{array}{llll}\text { University degree } & 0.42 * *(0.2 \mathrm{I}) & \mathrm{I} .53 & \mathrm{I} .0 \mathrm{I}-2.33\end{array}$

Model 2 Sociodemographic + clinical variables

$\begin{array}{llll}\text { Variables } & \text { B (SE) } & \text { OR } & 95 \% \mathrm{Cl}\end{array}$

$\begin{array}{llll}\text { Female gender } & 0.13(0.17) & 1.14 & 0.82-1.60\end{array}$

$\begin{array}{llll}\text { Age } & 0.03^{*}(0.00) & 1.03 & 1.02-1.04\end{array}$

$\begin{array}{llll}\text { University degree } & 0.48^{* *}(0.22) & 1.63 & 1.05-2.53\end{array}$

Diagnosis of depression $\quad-0.35(0.20) \quad 0.70 \quad 0.47-1.06$

Diagnosis of anxiety $\quad-0.46 * *(0.24) \quad 0.63 \quad 0.39-1.01$

Model 3 Sociodemographic + clinical + attitudinal variables

$\begin{array}{llll}\text { Variables } & B(S E) & O R & 95 \% \mathrm{Cl}\end{array}$

$\begin{array}{llll}\text { Female gender } \quad 0.13(0.17) & \text { I.16 } & 0.82-1.63\end{array}$

$\begin{array}{llll}\text { Age } & 0.02 *(0.00) & 1.03 & 1.01-1.04\end{array}$

$\begin{array}{llll}\text { University degree } \quad 0.58^{* *}(0.23) & 1.79 & 1.14-2.80\end{array}$

Diagnosis of depression $\quad-0.35(0.20) \quad 0.70 \quad 0.47-1.06$

Diagnosis of anxiety $\quad-0.46 * *(0.24) \quad 0.63 \quad 0.39-1.01$

DAI-10 - Positive $=$ Pharmacophilia $\quad 0.98 *(0.16) \quad 2.67 \quad 1.92-3.72$

$\begin{array}{llll}\text { CPS - Passive } \quad 0.55(0.33) & 1.74 & 0.90-3.33\end{array}$

Model 4 Sociodemographic + clinical + attitudinal + perceived health control variables

\begin{tabular}{llll} 
Variables & $\mathrm{B}(\mathrm{SE})$ & $\mathrm{OR}$ & $95 \% \mathrm{Cl}$ \\
Age & $0.02^{*}(0.00)$ & $\mathrm{I} .02$ & $\mathrm{I} .0 \mathrm{I}-\mathrm{I} .04$ \\
University degree & $0.38(0.24)$ & $\mathrm{I} .47$ & $0.92-2.36$ \\
DAI- I0 - Positive = Pharmacophilia & $0.75^{*}(0.18)$ & 2.14 & $1.49-3.07$ \\
CPS - Passive & $0.59(0.34)$ & $\mathrm{I} .8 \mathrm{I}$ & $0.9 \mathrm{I}-3.60$ \\
MHLC-C Internal & $-0.03^{*}(0.0 \mathrm{I})$ & 0.97 & $0.94-0.99$ \\
MHLC-C Chance & $-0.04^{*}(0.0 \mathrm{I})$ & 0.95 & $0.93-0.97$ \\
MHLC-C Doctor & $0.07^{*}(0.02)$ & 1.07 & $1.02-1.13$ \\
\hline
\end{tabular}

Notes: ${ }^{\mathrm{a} O R}$ is the exponent of $\mathrm{B}$. $* P<0.01$, ${ }^{*} * P<0.05$.

Abbreviations: $\mathrm{B}, \beta$ coefficient in logistic regression; $\mathrm{Cl}$, confidence interval; $\mathrm{CPS}$, Control Preferences Scale; DAI-10, Drug Attitude Inventory - 10 Items; MHLC-C, Multidimensional Health Locus of Control Scale Form C; OR, odds ratio; SE, standard error.

effect, and attitudinal variables showed that pharmacophilia was significantly associated with higher adherence. Among the three perceived health control variables: two (internal and chance subscales of health locus of control) were associated with significantly lower adherence to treatment, while the other (doctor subscale of health locus of control) was associated with higher adherence. Neither psychological reactance nor self-efficacy showed a significant effect in predicting adherence when the other variables were in the equation.

\section{SEM}

In a second round of analyses, the model of treatment adherence including the abovementioned variables was examined through SEM to test the pattern of relationships in predicting adherence to treatment. The model was also tested for measurement invariance regarding pharmacophobia/pharmacophilia and diagnoses.
The structural model was achieved after 98 iterations using the Maximum Likelihood Estimation. The minimum function test statistic was 282.267 (163), and the robust estimation was 264.705 (163). Figure 2 shows the values for the main coefficients found.

According to the SEM analyses performed (Figure 2), the distances between observed and expected matrices $(\mathrm{S}-\Sigma)$ were large and significant $\left(\chi^{2}[163]=303.696 ; P \leq 0.001\right)$. We assumed, therefore, that the matrices were different, reflecting the incremental adjustment indexes (NFI $=0.92$, Non Normed Fit Index $=0.95$ and CFI $=0.96$ ), and nonincremental adjustment indexes (GFI $=0.99$, and AGFI $=0.99$ ); a morethan-adequate adjustment. The RMSEA was 0.03 with a Confidence Interval (CI) of 0.024-0.035, which indicated minimal discrepancy between the variance and covariance matrixes of the observed data and the data reproduced from the model. We could therefore establish the goodness of a four-way model in the prediction of MMAS- 8 that encompasses the scores from internal health locus of control, doctors' health locus of control, cognitive psychological reactance, and age.

As can be observed from Figure 2, adherence is influenced by cognitive psychological reactance (negatively correlated: adherence decreases as cognitive psychological reactance increases) and by two of the dimensions of the health locus of control. One dimension is patients' trust in their psychiatrists (doctors' subscale), which is positively correlated; the second dimension is patients' beliefs that they are the ones controlling their mental health and that their mental health depends on their own actions (internal subscale), which is negatively correlated. Age was also weakly associated with psychiatric patients' treatment adherence - adherence increased as patients aged. Self-efficacy was indirectly related to treatment adherence through its direct relationship with the internal health locus of control. The abovementioned data gives a profile of the adherent psychiatric patient as someone with low cognitive psychological reactance, high trust in his or her psychiatrist, older age, and low self-confidence.

Finally, an analysis of the invariance measurement of the obtained SEM tested the effects of attitude toward treatment (DAI-10 score), pharmacophilia vs pharmacophobia, and diagnoses. In the invariant model, neither variable, DAI-10 score $\left(\chi^{2}[8]=14.33, P>0.05\right)$, nor diagnosis $\left(\chi^{2}[16]=14.41\right.$, $P>0.05$ ) was significant, implying that the SEM did not depend on patients' DAI-10 scores or on their diagnoses.

\section{Discussion}

The results of this research highlight the relevance of perceived health control variables in understanding psychiatric patients' 


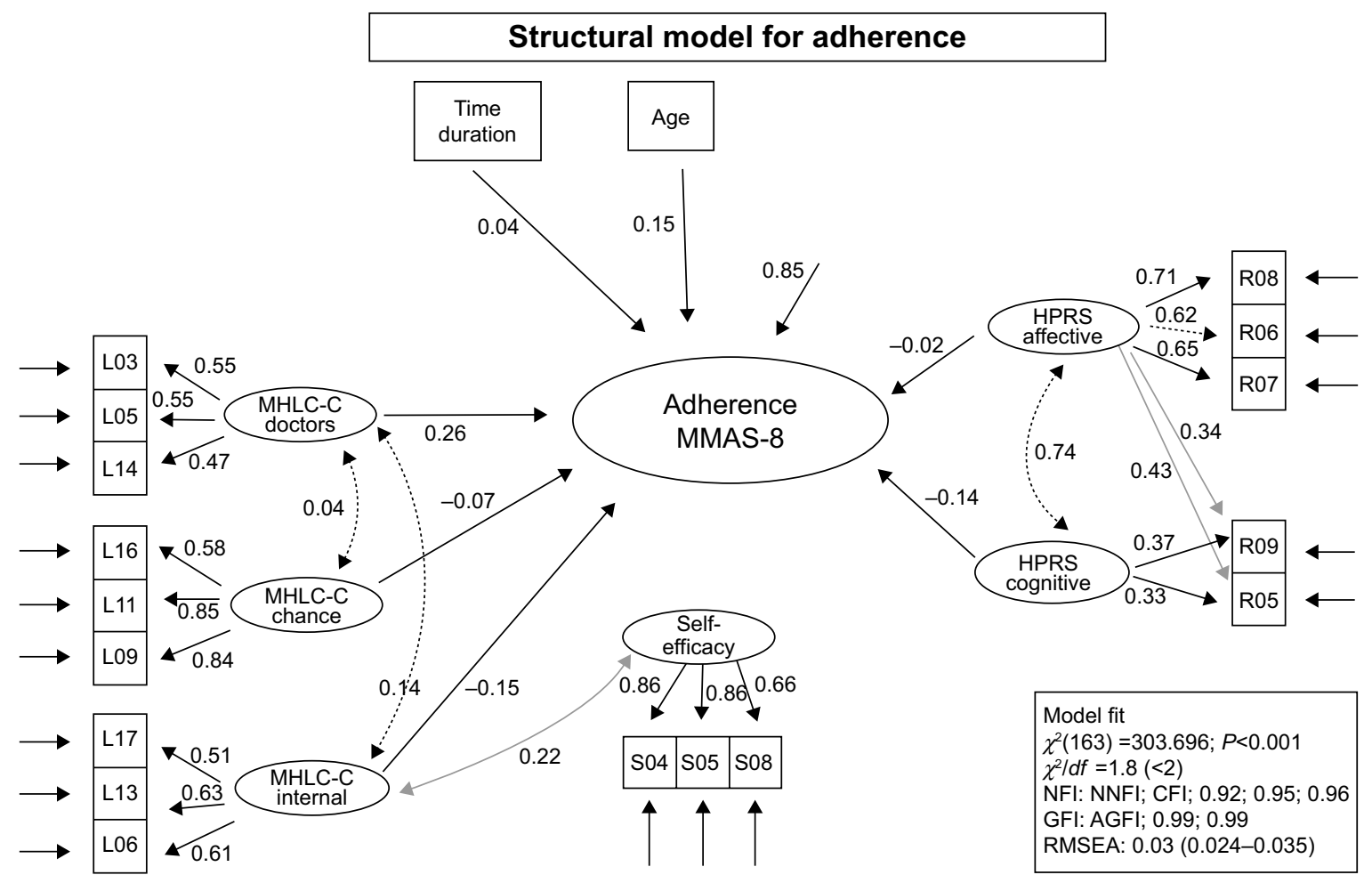

Figure 2 SEM analysis (standardized values) of data outlined after the framework for treatment adherence, according to MMAS-8 scale scores.

Note: Use of the MMAS-8 is protected by the US copyright laws. Permission for use is required. A licensure agreement is available from Donald E Morisky, ScD, ScM, MSPH, Professor, Department of Community Health Sciences, UCL A School of Public Health, 650 Charles E Young Drive South, Los Angeles, CA 90095-I772; dmorisky@gmail.com. Abbreviations: AGFI, $\chi^{2}$ Adjusted Goodness of Fit Index; CFI, Comparative Fit Index; GFI, $\chi^{2}$ Goodness of Fit Index; HPRS, Hong Psychological Reactance Scale; MHLC-C, Multidimensional Health Locus of Control Scale, Form C; MMAS-8, Morisky Medication Adherence Scale; NFI, Normed Fit Index; NNFI, Non Normed Fit Index; RMSEA, Root Mean Square Error of Approximation; SEM, Structural Equation Modelling.

level of adherence to psychopharmacological medications. Little attention has been paid to date to basic processes such as the role of psychological reactance, health locus of control, or self-efficacy in relation to treatment adherence.

The study of these psychological features is especially relevant, since each patient's own health control variables determine his or her approach toward the administered diagnostic and therapeutic interventions, which affects adherence to treatment ${ }^{29}$ and, consequently, the prognosis of such a patient. ${ }^{50}$

In our study, two of these processes (psychological reactance and health locus of control) had a direct association with adherence, whereas self-efficacy had an indirect relationship via health locus of control. Significantly, these processes appear to have had a more relevant role than traditional variables associated with treatment adherence (such as the complexity of treatment, treatment duration, or diagnosis).

Cognitive psychological reactance was negatively correlated with treatment adherence; patients' adherence decreased as their cognitive psychological reactance increased. Since a psychiatrist's message concerning adherence to prescribed treatment can inadvertently threaten the freedom of a psychiatric patient and create psychological reactance, which in turn motivates the patient to reject the prescribed treatment, ${ }^{51}$ it appears essential that psychiatrists learn communication techniques and counseling skills that allow them to avoid this communication barrier.

Although the effectiveness of interventions to limit or prevent psychological reactance in the doctor-patient relationship is yet to be proven, it has been suggested that psychological reactance could be prevented or limited by giving patients the feeling that they still hold some control over the process of care and that the "impositions" on their freedoms are acceptable because they have had the opportunity to decide about them. ${ }^{52,53}$ This feeling of control could be achieved through the empowering of patients through their participation in decision-making about their treatment. ${ }^{54}$

Regarding patients' health locus of control, the analyses performed showed positive associations between doctors' health locus of control and patients' adherence and a negative association between internal health locus of control and adherence to prescribed treatment. These results have obvious clinical implications. 
The association between a patient's belief that his/her mental health is due to the actions of his/her psychiatrist and the patient's adherence to treatment stresses the relevance of the patient's belief in the psychiatrist. Doctor-patient relationships in psychiatry are based on trust. ${ }^{55} \mathrm{~A}$ psychiatric patient needs to trust what his/her psychiatrist says in order to try offered treatments that are often unpleasant and require time to relieve symptoms. Patients come to a psychiatrist not only with their presenting symptoms but also with certain expectations about the various treatment modalities available as well as expectations about the outcome. As the saying goes, trust is earned, but it is also lost. Trust in a mental health professional depends on the patient's relationship expectations and experiences. When trust is broken with a doctor, it may affect relationships with every current and future doctorpatient interaction. Trust in a doctor implies a certain degree of patient uncertainty and the willingness to be vulnerable to the action of the mental health professional, being confident in the intentions and motives of the psychiatrist. ${ }^{56}$

On the other hand, a psychiatric patient's belief that his/her mental health is a function of his/her own behavior was associated with poor adherence. Psychiatric patients with an internal health locus of control may make a deliberate decision not to adhere to the psychopharmacological medications prescribed if they perceive themselves to be well or when the balance between their treatment regimens and their quality of life allows them to exercise control over their own disease management. ${ }^{30}$

Given the importance highlighted in this study between health locus of control and treatment adherence, more research is needed to develop targeted interventions that could modify these beliefs and related factors. Although locus of control tends to be stable over time and is not easy to change, cognitive training that targets reasoning can modify the sense of personal control. ${ }^{57}$

Although self-efficacy does not have a significant direct relationship with adherence, this control belief registered an indirect association with treatment adherence through internal health locus of control. Psychiatric patients' self-efficacy showed a positive association with internal health locus of control, therefore increasing as self-efficacy increased. Thus, psychiatric patients with a combination of high self-efficacy and high internal locus of control, in other words, those who believe they are both responsible for their own health and have the capacity to perform behaviors to maintain health, registered poor adherence to prescribed treatment.

Finally, these data can be taken as a first step in the development of new health education programs fostering adherence to treatment, as a clear requisite to improving the health status of patients with mental disorders. These programs require the direct involvement of patients according to their personal characteristics, ${ }^{58,59}$ but also require the involvement of clinicians in the management of those personal features, as we pointed out earlier.

\section{Limitations and strengths}

The main methodological limitations of this study include the fact that it was of a cross-sectional type, where data were collected on the whole study population at a single point in time to examine the relationship between adherence and the variables of interest, which enable the possibility of causal conclusions. Future prospective studies need to collect baseline data on variables of interest and establish how well they predict future adherence, for example, after a year.

This study also employed a number of self-report scales to assess adherence and perceived control constructs, but there is an inherent risk of self-report bias confounding the data. At the present time, many direct and indirect methods for measuring adherence are available. Each method has advantages and disadvantages, and no method is considered the gold standard. Patient questionnaires, ie, patient self-reports, are the most useful method in the clinical setting since they are simple, inexpensive, and effectively measure adherence. ${ }^{60-63}$ The aim of our study was to identify potential predictors of compliance with drug treatment of psychiatric outpatients in the community mental health care setting, paying special attention to beliefs and attitudes of psychiatric patients toward their prescribed treatment and toward partnership in medicinetaking. If we want to know how people feel about a certain thing, it seems most natural to ask them directly about their feelings. Direct questioning through self-report, therefore, has been an appealing method for studying attitudes. Traditional criticisms of self-report methodologies, especially response biases, are taken into account in the construction and utilization of questionnaires and in the analysis and interpretation of data derived from them.

We acknowledge that our statistical approach provides a model of adherence to psychopharmacological medications with the idea that there are average patients; however, different patients may have different cognitive styles, and so personalized intervention targeting each patient's cognitive style may be needed. ${ }^{64}$ Box 1 stresses this limitation but also provides our current recommendations for clinicians on how to promote adherence to psychopharmacological medications during long-term outpatient treatment. 
Box I Suggestions for promoting better adherence to psychopharmacological treatment in clinical practice

Our results indicated that the best ways to promote adherence to psychopharmacological medications during long-term outpatient treatment include:

I. Lack of coercion while treatments are being considered

2. A positive relationship between the patient and the treating clinicians

3. Use of verbal persuasion to convince the patient when needed

4. Use of empathy to understand the patient, teaching empathy to the patient, and use of examples of other people to whom the patient can identify (vicariousness) , rather than confronting the patient

5. Patient involvement in treatment decisions (patient empowerment)

6. Regarding ADRs: discussion of potential ADRs in advance, reduction of ADRs as much as possible and, when present, discussion and use of a risk-benefit analysis.

Our statistical approach provides a model of adherence to psychopharmacological medications with the idea that there are average patients. We acknowledge that in each patient, different variables may be particularly important and that some extreme patients may not be well represented by this model. As a matter of fact, we think that in some patients poor adherence may be mainly explained by pharmacophobia or high psychological reactance or high trust in their own responsibility and capacity for maintaining their own health. In other patients, lower levels of multiple factors may contribute to poor adherence. Future studies aimed at improving adherence to psychopharmacological medication prescription should plan on developing specific intervention approaches targeting the cognitive style of each patient.

Notes: aVicariousness refers to qualities or scenarios wherein one's experiences occur through another person. For further reading on this topic please see de Leon and De Las Cuevas. ${ }^{64}$

Abbreviation: ADR, adverse drug reaction.

The strengths of the study include the large number of patients participating in the study; the large number of sociodemographic, clinical, and perceived control variables included; and that the SEM performed represents a broad dataanalytic framework with flexible and unique capabilities.

\section{Conclusion}

This study provides support for the hypothesis that perceived health control variables play a relevant role in psychiatric patients' adherence to psychopharmacological medications. The findings highlight the importance of considering prospective studies of patients' psychological reactance and health locus of control as they may be clinically relevant factors contributing to adherence to psychopharmacological medication regimens.

\section{Acknowledgments}

The authors acknowledge Lorraine Maw, MA, at the Mental Health Research Center at Eastern State Hospital, Lexington, $\mathrm{KY}$, USA, who helped in editing this article.

\section{Disclosure}

No commercial organizations had any role in the completion or publication of this study. The authors report no conflicts of interest in this work.

\section{References}

1. De las Cuevas C. Towards a clarification of terminology in medicine taking behavior: compliance, adherence and concordance are related although different terms with different uses. Curr Clin Pharmacol. 2011;6(2):74-77.

2. Farooq S, Naeem F. Tackling nonadherence in psychiatric disorders: current opinion. Neuropsychiatr Dis Treat. 2014;10:1069-1077.
3. Bambauer KZ, Soumerai SB, Adams AS, Zhang F, Ross-Degnan D. Provider and patient characteristics associated with antidepressant nonadherence: the impact of provider specialty. J Clin Psychiatry. 2007;68(6):867-873.

4. Yeh MY, Sung SC, Yorker BC, Sun CC, Kuo YL. Predictors of adherence to an antidepressant medication regimen among patients diagnosed with depression in Taiwan. Issues Ment Health Nurs. 2008;29(7):701-717.

5. Sawada N, Uchida H, Suzuki T, et al. Persistence and compliance to antidepressant treatment in patients with depression: a chart review. BMC Psychiatry. 2009;9:38.

6. Shigemura J, Ogawa T, Yoshino A, Sato Y, Nomura S. Predictors of antidepressant adherence: results of a Japanese Internet-based survey. Psychiatry Clin Neurosci. 2010;64(2):179-186.

7. Lee MS, Lee HY, Kang SG, et al. Variables influencing antidepressant medication adherence for treating outpatients with depressive disorders. $J$ Affect Disord. 2010;123(1-3):216-221.

8. Lacro JP, Dunn LB, Dolder CR, Leckband SG, Jeste DV. Prevalence of and risk factors for medication nonadherence in patients with schizophrenia: a comprehensive review of recent literature. J Clin Psychiatry. 2002;63(10):892-909.

9. Valenstein M, Ganoczy D, McCarthy JF, Myra Kim H, Lee TA, Blow FC. Antipsychotic adherence over time among patients receiving treatment for schizophrenia: a retrospective review. J Clin Psychiatry. 2006; 67(10):1542-1550.

10. Lingam R, Scott J. Treatment non-adherence in affective disorders. Acta Psychiatr Scand. 2002;105(3):164-172.

11. García S, Martínez-Cengotitabengoa M, López-Zurbano S, et al. Adherence to antipsychotic medication in bipolar disorder and schizophrenic patients: a systematic review. J Clin Psychopharmacol. 2016; 36(4):355-371.

12. Chapman SC, Horne R. Medication nonadherence and psychiatry. Curr Opin Psychiatry. 2013;26(5):446-452.

13. Leucht S, Heres S. Epidemiology, clinical consequences, and psychosocial treatment of nonadherence in schizophrenia. J Clin Psychiatry. 2006;67(Suppl 5):3-8.

14. San L, Bernardo M, Gómez A, Martínez P, González B, Peña M. Socio-demographic, clinical and treatment characteristics of relapsing schizophrenic patients. Nord J Psychiatry. 2013;67(1):22-29.

15. Witt K, van Dorn R, Fazel S. Risk factors for violence in psychosis: systematic review and meta-regression analysis of 110 studies. PLoS One. 2013;8(2):e55942. 
16. Ruengorn C, Sanichwankul K, Niwatananun W, Mahatnirunkul S, Pumpaisalchai W, Patumanond J. A risk-scoring scheme for suicide attempts among patients with bipolar disorder in a Thai patient cohort. Psychol Res Behav Manag. 2012;5:37-45.

17. Simpson SH, Eurich DT, Majumdar SR, et al. A meta-analysis of the association between adherence to drug therapy and mortality. BMJ. 2006;333(7557):15.

18. Cullen BA, McGinty EE, Zhang Y, et al. Guideline-concordant antipsychotic use and mortality in schizophrenia. Schizophr Bull. 2013;39(5) 1159-1168.

19. Thieda P, Beard S, Richter A, Kane J. An economic review of compliance with medication therapy in the treatment of schizophrenia Psychiatr Serv. 2003;54(4):508-516.

20. Burton WN, Chen CY, Conti DJ, Schultz AB, Edington DW. The association of antidepressant medication adherence with employee disability absences. Am J Manag Care. 2007;13(2):105-112.

21. Bagalman E, Yu-Isenberg KS, Durden E, Crivera C, Dirani R, Bunn WB. Indirect costs associated with nonadherence to treatment for bipolar disorder. J Occup Environ Med. 2010;52(5):478-485

22. Sabaté E. Adherence to Long-Term Therapies: Evidence for Action. Geneva, Switzerland: World Health Organization; 2003.

23. Jónsdóttir H, Opjordsmoen S, Birkenaes AB, et al. Predictors of medication adherence in patients with schizophrenia and bipolar disorder. Acta Psychiatr Scand. 2013;127(1):23-33.

24. Rivero-Santana A, Perestelo-Perez L, Pérez-Ramos J, Serrano-Aguilar P, De las Cuevas C. Sociodemographic and clinical predictors of compliance with antidepressants for depressive disorders: systematic review of observational studies. Patient Prefer Adherence. 2013;7:151-169.

25. Medic G, Higashi K, Littlewood KJ, Diez T, Granström O, Kahn RS. Dosing frequency and adherence in chronic psychiatric disease: systematic review and meta-analysis. Neuropsychiatr Dis Treat. 2013;9:119-131.

26. De las Cuevas C, Peñate W, Sanz EJ. Risk factors for non-adherence to antidepressant treatment in patients with mood disorders. Eur J Clin Pharmacol. 2014;70(1):89-98.

27. Richardson M, McCabe R, Priebe S. Are attitudes towards medication adherence associated with medication adherence behaviours among patients with psychosis? A systematic review and meta analysis. Soc Psychiatry Psychiatr Epidemiol. 2013;48(4):649-657.

28. De las Cuevas C, Peñate W. Explaining pharmacophobia and pharmacophilia in psychiatric patients: relationship with treatment adherence. Hum Psychopharmacol. 2015;30(5):377-383.

29. De las Cuevas C, Peñate W, Sanz EJ. The relationship of psychological reactance, health locus of control and sense of self-efficacy with adherence to treatment in psychiatric outpatients with depression. BMC Psychiatry. 2014;14:324.

30. De las Cuevas C, Peñate W, Cabrera C. Perceived health control: a promising step forward in our understanding of treatment adherence in psychiatric care. J Clin Psychiatry. 2016;77(10):e1233-e1239.

31. De las Cuevas C, de Leon J. Reviving research on medication attitudes for improving pharmacotherapy: focusing on adherence. Psychother Psychosom. 2017;86(2):73-79.

32. Jöreskog KG. Analyzing psychological data by structural analysis of covariance matrices. In: Atkinson RC, Krantz DH, Luce RD, Suppes P, editors. Contemporary Developments in Mathematical Psychology. San Francisco, CA: Freeman; 1974:1-56.

33. Jöreskog KG, Sörbom D. Recent developments in structural equation modeling. J Mark Res. 1982;19(4):404-416.

34. World Health Organization. International Statistical Classification of Diseases and Related Problems, 10th revision (ICD-10). Geneva, Switzerland: World Health Organization; 1992.

35. Hogan TP, Awad AG, Eastwood R. A self-report scale predictive of drug compliance in schizophrenics: reliability and discriminative validity. Psychol Med. 1983;13(1):177-183.

36. Robles-García R, Salazar-Alvarado V, Páez-Agraz F, Ramírez-Barreto F. Assessment of drug attitudes in patients with schizophrenia: psychometric properties of the DAI Spanish version. Actas Esp Psiquiatr. 2004 32(3):138-142.
37. Degner LF, Sloan JA, Venkatesh P. The control preferences scale. Can J Nurs Res. 1997;29(3):21-43.

38. De las Cuevas C, Peñate W. Validity of the control preferences scale in patients with emotional disorders. Patient Prefer Adherence. 2016;10: 2351-2356.

39. Wallston KA, Stein MJ, Smith CA. Form C of the MHLC scales: a condition-specific measure of locus of control. JPers Assess. 1994;63(3): 534-553.

40. De las Cuevas C, Peñate W, Betancort M, Cabrera C. What do psychiatric patients believe regarding where control over their illness lies? Validation of the multidimensional health locus of control scale in psychiatric outpatient care. J Nerv Ment Dis. 2015;203(2):81-86.

41. Schwarzer R, Jerusalem M. Generalized Self-Efficacy scale. In: Weinman J, Wright S, Johnston M, editors. Measures in Health Psychology: A User's Portfolio. Causal and Control Beliefs. Windsor, England: NFER-NELSON; 1995:35-37.

42. De las Cuevas C, Peñate W. Validation of the General Self-Efficacy Scale in psychiatric outpatient care. Psicothema. 2015;27(4):410-415.

43. Hong SM, Faedda S. Refinement of the Hong psychological reactance scale. Educ Psychol Meas. 1996;56(1):173-182.

44. De las Cuevas C, Peñate W, Betancort M, De Rivera L. Psychological reactance in psychiatric patients: examining the dimensionality and correlates of the Hong Psychological Reactance Scale in a large clinical sample. Pers Individ Dif. 2014;70:85-91.

45. Morisky DE, Ang A, Krousel-Wood M, Ward H. Predictive validity of a medication adherence measure in an outpatient setting. $J$ Clin Hypertens. 2008;10(5):348-354.

46. De las Cuevas C, Peñate W. Psychometric properties of the eight-Item Morisky Medication Adherence Scale (MMAS-8) in psychiatric outpatient setting. Int J Clin Health Psychol. 2015;15(2):121-129.

47. R Core Team. R: A Language and Environment for Statistical Computing. Vienna, Austria: R Foundation for Statistical Computing; 2014. Available from: http://www.R-project.org/. Accessed 15 November, 2016.

48. Hernández Cabrera JA. ULLRToolBox Home, 2013. Available from: https://sites.google.com/site/ullrtoolboxeng/. Accessed 15 November, 2016.

49. Rosseel Y. Lavaan: an R Package for structural equation modeling. J Stat Softw. 2012;48:1-36.

50. Hays RD, Kravitz RL, Mazel RM, et al. The impact of patient adherence on health outcomes for patients with chronic disease in the Medical Outcomes Study. J Behav Med. 1994;17(4):347-360.

51. Worchel S, Brehm JW. Effects of threats to attitudinal freedom as a function of agreement with the communicator. J Pers Soc Psychol. 1970; 14(1):18-22.

52. Fogarty JS. Reactance theory and patient noncompliance. Soc Sci Med. 1997;45(8):1277-1288.

53. Bigi S. Communication skills for patient engagement: argumentation competencies as means to prevent or limit reactance arousal, with an example from the Italian healthcare system. Front Psychol. 2016; 27(7):1472.

54. De las Cuevas C, Peñate W, de Rivera L. To what extent is treatment adherence of psychiatric patients influenced by their participation in shared decision making? Patient Prefer Adherence. 2014;8: 1547-1553.

55. Lakdawala PD. Doctor-patient relationship in psychiatry. Mens Sana Monogr. 2015;13:82-90.

56. Verhaeghe M, Bracke P. Stigma and trust among mental health service users. Arch Psychiatr Nursing. 2011;25(4):294-302.

57. Waller KV, Bates RC. Health locus of control and self-efficacy beliefs in a healthy elderly sample. Am J Health Promot. 1992;6(4):302-309.

58. Wolinsky FD, Vander Weg MW, Martin R, et al. Does cognitive training improve internal locus of control among older adults? J Gerontol B Psychol Sci Soc Sci. 2010;65(5):591-598.

59. Berglund E, Lytsy P, Westerling R. The influence of locus of control on self-rated health in context of chronic disease: a structural equation modeling approach in a cross sectional study. BMC Public Health. 2014; 23(14):492. 
60. Osterberg L, Blaschke T. Adherence to medication. N Engl J Med. 2005; 353(5):487-497.

61. Walsh JC, Mandalia S, Gazzard BG. Responses to a 1 month self-report on adherence to antiretroviral therapy are consistent with electronic data and virological treatment outcome. AIDS. 2002;16(2):269-277.

62. Haynes RB, Taylor DW, Sackett DL, Gibson ES, Bernholz CD, Mukherjee J. Can simple clinical measurements detect patient noncompliance? Hypertension. 1980;2(6):757-764.
63. Vermeire E, Hearnshaw H, Van Royen P, Denekens J. Patient adherence to treatment: three decades of research. A comprehensive review. J Clin Pharm Ther. 2001;26(5):331-342.

64. de Leon J, De Las Cuevas C. The art of pharmacotherapy: reflections on pharmacophobia. J Clin Psychopharmacol. 2017;37(2):131-137.

Patient Preference and Adherence

Dovepress

\section{Publish your work in this journal}

Patient Preference and Adherence is an international, peer-reviewed, open access journal that focuses on the growing importance of patient preference and adherence throughout the therapeutic continuum. Patient satisfaction, acceptability, quality of life, compliance, persistence and their role in developing new therapeutic modalities and compounds to optimize clinical outcomes for existing disease states are major areas of interest for the journal. This journal has been accepted for indexing on PubMed Central. The manuscript management system is completely online and includes a very quick and fair peer-review system, which is all easy to use. Visit http://www. dovepress.com/testimonials.php to read real quotes from published authors.

Submit your manuscript here: http://www.dovepress.com/patient-preference-and-adherence-journal 